\title{
Abuso sexual infantil e aprendizagem: caminhos possíveis na psicopedagogia
}

\author{
Child sexual abuse and learning: possible paths in psychopedagogy \\ Abuso sexual infantil y aprendizaje: posibles caminos en psicopedagogía
}

Recebido: 31/08/2021 | Revisado: 09/09/2021 | Aceito: 10/09/2021 | Publicado: 12/09/2021

Francisco Vladeilson Lima Pereira ORCID: https://orcid.org/0000-0001-5027-6812

Universidade de Fortaleza, Brasil

E-mail: valdeilson_lima@hotmail.com

Dina Mara Formiga da Silva

ORCID: https://orcid.org/0000-0002-5387-7194 Universidade Estadual do Ceará, Brasil

E-mail: dinamara_silva@hotmail.com

Maria do Socorro Tavares Timbó

ORCID: https://orcid.org/0000-0001-6508-5875

Universidade de Lisboa, Lisboa

E-mail: msttimbo@yahoo.com.br

Cristiane Sales Leitão

ORCID: https://orcid.org/0000-0002-8412-0629 Assembleia Legislativa do Ceará, Brasil E-mail: cristianesalesleitao@gmail.com

Ana Cecília Sales Barreto Leitão

ORCID: https://orcid.org/0000-0003-1657-5733 Centro Universitário Unichristus, Brasil E-mail: ceciliasalesleitão@gmail.com

Lídia Andrade Lourinho

ORCID: https://orcid.org/0000-0002-5883-9007

Faculdade Luciano Feijão, Brasil

E-mail: lidialourinho@ hotmail.com

\begin{abstract}
Resumo
Objetivo: discutir a atuação do psicopedagogo nos casos em que o sujeito aprendente foi abusado sexualmente e sua aprendizagem esteja perpassada pela história de violência sofrida. Método: pesquisa exploratória bibliográfica, onde foram utilizados artigos científicos disponibilizados nas principais plataformas online e livros que abarcam diferentes áreas, como educação, psicologia, sociologia, psicopedagogia e saúde. Resultados e Discussão: Constatou-se que, na intervenção psicopedagógica que envolve a criança abusada, o profissional deve atuar visando o estabelecimento do vínculo afetivo com a criança a fim de efetivar seu trabalho, reconhecendo a sua própria subjetividade na relação. Considerações Finais: Concluiu-se o estudo com a constatação de que a Psicopedagogia tem muito a contribuir com ações preventivas que visem principalmente o autocuidado e com ações interventivas no sentido de reconfigurar as modalidades de aprendizagem que possam estar enrijecidas por mecanismos emocionais e afetivos oriundos das relações abusivas sofridas.
\end{abstract}

Palavras-chave: Psicopedagogia; Abuso sexual infantil; Aprendizagem.

\begin{abstract}
Objective: to discuss the psychopedagogue's performance in cases where the learning subject was sexually abused and his learning is permeated by the history of violence suffered. Method: exploratory bibliographic research, where scientific articles were used available in the main online platforms and books that cover different areas, such as education, psychology, sociology, psychopedagogy and health. Results and Discussion: It was found that, in the psychopedagogical intervention involving the abused child, the professional should act aiming at establishing the affective bond with the child in order to perform their work, recognizing their own subjectivity in the relationship. Final Considerations: The study was concluded with the finding that Psychopedagogy has much to contribute to preventive actions aimed mainly at self-care and interventional actions in order to reconfigure the learning modalities that may be stiffened by emotional and affective mechanisms arising from the abusive relationships suffered.
\end{abstract}

Keywords: Psychopedagogy; Child sexual abuse; Apprenticeship.

\section{Resumen}

Objetivo: discutir el desempeño del psicopedagogo en los casos en que el sujeto de aprendizaje fue abusado sexualmente y su aprendizaje está impregnado por la historia de violencia sufrida. Método: investigación bibliográfica exploratoria, donde se utilizaron artículos científicos disponibles en las principales plataformas online y libros que 
abarcan diferentes áreas, como educación, psicología, sociología, psicopedagogía y salud. Resultados y Discusión: Se encontró que, en la intervención psicopedagógica que involucra al niño maltrato, el profesional debe actuar con el objetivo de establecer el vínculo afectivo con el niño para poder realizar su trabajo, reconociendo su propia subjetividad en la relación. Consideraciones finales: El estudio concluyó con el hallazgo de que la Psicopedagogía tiene mucho que aportar a las acciones preventivas dirigidas principalmente al autocuidado y a las acciones intervencionistas con el fin de reconfigurar las modalidades de aprendizaje que pueden verse endurecidas por los mecanismos emocionales y afectivos derivados de las relaciones abusivas sufridas.

Palabras clave: Psicopedagogía; Abuso sexual infantil; Aprendizaje.

\section{Introdução}

A aprendizagem é um importante processo que vem sendo estudado por diversas áreas do conhecimento e que constitui tema bastante complexo e abrangente. Por sua complexidade, muitas definições e explicações de como ocorre este processo foram forjadas ao longo da história sem, contudo, esgotar o tema. A partir das discussões e dos avanços que se teve na compreensão de como ocorre a aprendizagem, foram sendo percebidos aspectos presentes e importantes neste processo em que, dentre estes, pode-se citar a história de vida do sujeito que aprende e suas relações familiares, por exemplo. Estes aspectos estão envolvidos com a maneira única e singular de cada pessoa se relacionar com o conhecimento e, portanto, com a aprendizagem.

Infelizmente, a história de vida de muitas crianças é permeada por violência e maus tratos, onde o abuso sexual configura-se como um deles. Este tipo de maus-tratos ocorre em todo o mundo e em todas as classes socioeconômicas sendo, portanto, uma grave problemática diante dos seus possíveis efeitos. Na maioria das vezes a violência é perpetrada por familiares próximos à criança ou pessoas que fazem parte do seu convívio social, o que pode acarretar sérios reflexos no estabelecimento de seus vínculos afetivos e em sua percepção de mundo, bem como de si mesma (Aded et al. 2006; Florentino, 2015; Sanderson, 2005; Mello, 2008).

Portanto, sendo a Psicopedagogia uma área do conhecimento cujo objeto de estudo é a aprendizagem humana, bem como os aspectos presentes neste processo, e considerando também a problemática do abuso sexual na infância, é possível levantar o seguinte questionamento: De que forma o abuso sexual vivenciado na infância pode vir a impactar o ato de aprender do indivíduo? Mais ainda: Qual o olhar da Psicopedagogia para o fenômeno do abuso sexual na infância e de que maneira pode vir a atuar nesse caso? Qual seria o papel do profissional da psicopedagogia? Quão significativo o seu trabalho pode ser na vida da criança violada? Além disso, quais meios poderia este profissional se servir a fim de realizar um trabalho efetivo com este sujeito? (Bossa, 2000; Masini, 2015; Nunes \& Silveira, 2008).

Tais perguntas nortearam o presente trabalho, que tem como objetivo: discutir a atuação do psicopedagogo nos casos em o sujeito aprendente foi abusado sexualmente e sua aprendizagem esteja perpassada pela história de violência sofrida.

\section{Metodologia}

A presente pesquisa foi realizada com base na pesquisa exploratória bibliográfica, que, de segundo Gil (2007), proporcionar uma maior familiaridade com o problema, com o intuito de torná-lo mais explícito ou de construir hipóteses. Normalmente é concebida a partir de material já elaborado, composto principalmente de livros e artigos científicos. Apesar da maioria dos estudos apresentarem a necessidade da pesquisa bibliográfica, há pesquisas desenvolvidas unicamente a partir de fontes bibliográficas.

Este artigo foi construído a partir de estudos descritos com abordagem qualitativa, e tem como objetivo principal, de acordo com Campos (2000), apresentar ou analisar as características de um determinado fenômeno. 
Para laboração do trabalho, foram utilizados artigos científicos disponibilizados nas principais plataformas online e livros que abarcam diferentes áreas, como educação, psicologia, sociologia, psicopedagogia e saúde, tipificando a pesquisa documental.

A pesquisa documental utiliza-se de documentos, escritos ou não, como fonte primária de dados. Segue os mesmos caminhos da pesquisa bibliográfica, e por vezes não é fácil distingui-las. De acordo com Fonseca (2002), a pesquisa bibliográfica faz uso de fontes constituídas por material já elaborado, formado basicamente por livros e artigos científicos localizados em bibliotecas físicas ou online e a pesquisa documental se beneficia de fontes mais diversificadas e dispersas, sem tratamento analítico, como: jornais, revistas, relatórios, documentos oficiais, cartas, filmes, fotografias, vídeos, etc As etapas metodológicas foram: leitura exaustiva, fichamentos e interpretação das referências.

\section{Resultados e Discussão}

\section{1 os traumas decorrentes do abuso sexual infantil}

O abuso sexual infantil é um tema que, ainda atualmente, representa um tabu. Isto decorre, dentre outras razões, do fato de tratar-se de um assunto delicado que envolve, na maioria das vezes, familiares ou pessoas próximas à criança que é vítima deste tipo de violência. Apesar de ser uma problemática presente desde os tempos antigos e de ter ganho maior visibilidade pelos meios de comunicação, carece ainda de discussões mais aprofundadas sobre o tema.

Tal discussão faz-se necessária para que se possa promover tanto uma maior conscientização por parte das pessoas quanto às consequências nefastas que este ato pode acarretar a longo e curto prazo na vida do indivíduo abusado para, então, definir formas e encontrar meios para prevenir contra tal violência que viola, dentre outros, os direitos sexuais (Stupiggia, 2009).

Definir o abuso sexual é bastante complexo e, por vezes, tal definição torna-se incompleta mediante os diversos elementos que podem estar envolvidos. Isso é evidente quando, ao verificar diversos autores que abordam o tema, percebe-se que foi deixado de considerar um ou outro aspecto do abuso sexual ou quando, numa tentativa de fazer convergir as diversas visões, a definição parece ganhar maiores contornos sem que seja possível delimitá-lo de forma precisa e exata.

O que, no entanto, parece ser da opinião de todos que estudam o tema é o fato de o abuso sexual ter consequências irremediáveis caso seja negligenciado. Tais consequências podem ainda ser potencializadas se o fato ocorrer na infância e houver reincidência. Maiores prejuízos se dão também quando ocorre de o abusador ser um ente próximo da criança, fato presente na maioria dos casos (Aded et al. 2006).

Ao longo dos tempos o conceito de infância passou por muitas transformações. Tais transformações e a própria ideia de infância estavam intrinsecamente ligadas às posições filosóficas elaboradas numa sociedade em um determinado momento sendo esta, portanto, uma construção histórica e social.

Antes da Modernidade, a criança era considerada um adulto em miniatura que diferia de um adulto apenas por suas proporções físicas. A vida era relativamente igual para todas as idades, não havendo a exigência de um preparo específico para aqueles que estavam à frente dos cuidados da criança (Ghiraldelli Junior, 2008).

As precárias condições higiênicas e de saúde do século XII, por exemplo, contribuíram para uma postura insensível em relação à infância. Tendo em vista os grandes índices de mortalidade infantil nesse período é possível inferir o descaso e a indisponibilidade de tempo dos pais para com as crianças frente a incerteza quanto à sobrevivência do minúsculo ser (Postman, 1999).

Portanto, as crianças não recebiam uma atenção especial sendo possível que fossem expostas a vários tipos de violência dos mais velhos, bem como incluídas em práticas sexuais. Não havia também a consciência social que admitisse a existência autônoma da infância como uma categoria diferenciada do gênero humano. Tudo isto mostra que a "criança sempre 
existiu, mas a infância não. $\mathrm{O}$ mundo pré-moderno não tem uma noção de infância. Todo esse cenário, no entanto, aproximadamente a partir do século XV, começa a mudar radicalmente" (Ghiraldelli Junior, 2008, p. 17).

Ghiraldelli Junior (2008) afirma ainda que a partir das ideias dos intelectuais no século XV, que incluía líderes religiosos, foi possível uma concepção de infância como uma fase na qual o ser humano faz coisas diferentes e possui sentimentos e pensamentos peculiares sendo, por isso, necessário um ambiente histórico-social propício de modo que esta fase pudesse ser superada da melhor forma.

A partir século XX é possível perceber uma maior preocupação com a infância, não apenas estabelecendo um padrão de cuidados caracterizando por um modo de ajuda à criança, mas também garantindo os direitos desta (Sanderson, 2005). No Brasil esse fato culmina com a criação do Estatuto da Criança e do Adolescente (ECA), instituído pela Lei $\mathrm{N}^{\circ}$ 8.069, de 13 de julho de 1990, sendo este um conjunto de normas do ordenamento jurídico brasileiro que objetiva proteger integralmente a criança e o adolescente como é salientado em seu Artigo $1^{\circ}$ (Ministério da Saúde, 1990).

O Estatuto da Criança e do Adolescente (ECA) define criança como uma pessoa com idade até doze anos incompletos e o adolescente entre doze e dezoito anos de idade, garantindo que estas gozem de todos os direitos fundamentais inerentes à pessoa e assegura ainda todas as oportunidades e facilidades a fim de lhes facultar o desenvolvimento físico, mental, moral, espiritual e social em condições de liberdade e de dignidade (Ministério da Saúde, 1990).

Diante das definições de criança e de adolescente que constam no ECA, percebe-se que estas são dadas levando em consideração a idade cronológica do indivíduo. No entanto, se por um lado existem padrões sequenciais de mudanças geneticamente programados aos quais todos os indivíduos estão sujeitos, estando estes ligados a fase de desenvolvimento que obedecem à ordem cronológica, há também aspectos não universais que deveriam ser levados em consideração na definição de infância como, por exemplo, a idade psicológica (Santos, Xavier \& Nunes, 2008).

Dentre as várias contribuições ao estudo do desenvolvimento humano, é possível encontrar as de Sigmund Freud que, empreendendo um estudo pioneiro sobre a formação do Inconsciente humano e sua relação com a sexualidade, aponta para a importância das experiências vividas na infância na formação da personalidade. Na perspectiva freudiana a sexualidade tem, portanto, um papel fundamental (Garcia-Rosa, 2009).

A sexualidade nas teorias freudianas esteve presente desde os primeiros momentos em que este se propôs a estudar as histéricas. Por meio da teoria do trauma, Freud explicava que a neurose se dava em decorrência de reminiscências, ou seja, lembranças, de uma suposta sedução sexual real que, a princípio, não produzia qualquer excitação sexual, mas que ao surgir a sexualidade na puberdade, esta lembrança poderia ser evocada tornando-se patogênica (Rudges, 2009).

No entanto, esta teoria perde força ante o fato de ser sempre recorrente nos relatos dos pacientes. Como salienta Freud, era necessário que todos os pais, inclusive o seu, fossem apontados como pervertidos. A teoria do trauma sede lugar então à teoria da fantasia. A teoria da fantasia explica que as memórias das seduções sofridas pelas pacientes são fantasia de impulsos edipianos de anormal intensidade. Entre em cena, a partir daí, não apenas o papel da fantasia, mas também a ideia de uma sexualidade infantil (ibdem).

Freud aponta para as fases de organização da libido (energia afetiva que mobiliza o organismo na perseguição dos seus objetivos) onde estas designam etapas de desenvolvimento sexual da criança e que são caracterizadas pela predominância de uma zona erógena ou ainda por um modo de relação com um objeto. Estas fases são: a oral, onde o prazer está ligado à ingestão de alimentos e à excitação da mucosa dos lábios, a sádica-anal que é caracterizada por uma organização da libido sob o primado da zona anal e a fase fálica onde há a predominância dos órgãos genitais sendo o objeto de pulsão para os meninos,a mãe, e para as meninas, primeiramente a mãe e posteriormente o pai (Garcia-Rosa, 2009).

Em suma, Freud explica que a forma pela qual o indivíduo atravessa a infância e vivencia as experiências nesta fase serão determinantes nos momentos posteriores da vida, ressaltando também a importância do papel dos pais na formação dos 
vínculos iniciais e futuros na vida de uma criança. Logo, existe uma estreita ligação entre as experiências vividas pelo indivíduo e seus pais na infância e a capacidade de estabelecer vínculos afetivos posteriormente (Almeida, 2011).

Logo, é possível perceber, sob a ótica psicanalítica, que o afeto de uma criança por seus pais é, sem dúvida, o traço infantil mais importante. Ressalta-se ainda a importância das relações entre uma criança e seus pais, sendo possível afirmar que qualquer distúrbio destas relações produzirá os mais graves efeitos, sendo determinante, por exemplo, para o surgimento das neuroses.

Diante de todo o exposto pode-se entrever quais as consequências do trauma decorrente do abuso sexual na infância. É cabível também o questionamento de como se dará a relação de uma criança abusada sexualmente com as aprendizagens, tal qual ocorrerá com o ensinante. No entanto, para discorrer sobre tais questões faz necessário entender o que é o trauma psicológico e quais seus reflexos na vida do indivíduo.

\subsection{Consequências do abuso sexual na infância}

É consenso entre aqueles que se dedicaram ao estudo do abuso sexual na infância que tal ato acarreta consequências graves e extensas não apenas psicológicas e emocionais, mas também físicas e sociais (Aded, 2006). Diante desse fato, faz-se necessário discorrer sobre quais os danos que uma criança pode sofrer ao ser vítima desse ato tão cruel que é o abuso sexual.

Para que não se caia num reducionismo e generalizações sobre as consequências do abuso sexual é importante que se tenha em mente que, embora este tipo de violência tenha sérios impactos sexuais, emocionais e psicológicos na criança violentada e que estes possam ser a curto e longo prazo, tais impactos podem variar consideravelmente (Sanderson, 2005).

Os efeitos do trauma sofrido pelo abuso estão relacionados com as condições ou predeterminação de cada indivíduo. É o que sugere Florentino (2015) ao afirmar que os efeitos do abuso sexual diversificam de acordo com as condições de cada indivíduo, entra elas: a idade da criança quando a violência teve início; a duração e quantidade de vezes em que ela foi violentada; o grau de violência utilizado; o tipo de vínculo existente entre o abusador e a vítima.

Além disso, para compreender as possíveis consequências do abuso é necessário que se considere também o contexto em que este ocorre, a situação da vítima em sua família, o impacto que a revelação do abuso pode acarretar as reações de pessoas conhecidas, as decisões sociais, médicas e judiciárias. Importante que se possa considerar também o fato de que há indivíduos que são capazes de reconstruir suas vidas, ressignificando suas experiências de modo a não apresentarem as sequelas descritas na literatura especializada (Aded, 2006; De Antoni, 2011).

Conclui-se assim que são bastante relativos os efeitos do abuso sexual tendo em vista o caráter singular do indivíduo e que, por isso, torna-se difícil, senão impossível, delimitar com precisão os efeitos por estes dependerem da particularidade da experiência de cada vítima. O abuso sexual pode ter consequências orgânicas como, por exemplo, "lesões físicas gerais; lesões genitais; lesões anais, doenças sexualmente transmissíveis; disfunções sexuais; hematomas; contusões e fraturas" (Florentino, 2015, p. 141).

Também, devido à violência sexual sofrida na infância, é possível que ocorra comprometimento no desenvolvimento neurológico da criança principalmente se ocorrer numa idade inferior a 3 (três) anos, idade em que o cérebro não está desenvolvido. É o que aponta Sanderson (2005, p. 171) ao afirmar que: “o estresse na infância precoce, um fator do abuso sexual em crianças, pode causar dano permanente à estrutura neural e à função do cérebro em desenvolvimento, deixando marcas indeléveis".

As crianças sexualmente abusadas podem apresentar também sentimento de culpa, depressão, baixa autoestima, timidez, agressividade, medo, embotamento afetivo, isolamento, dificuldade em confiar nos outros, alterações de sono, dores abdominais, fugas de casa, sexualidade exacerbada, entre outros podendo apresentar alguns transtornos associados ao abuso sexual como por exemplo, o Distúrbio de Estresse Pós-Traumático, o Transtorno de Déficit de Atenção e Hiperatividade 
(TDAH), Distúrbios de Conduta, Distúrbio de Personalidade Antissocial, Distúrbio de Personalidade Limítrofe, Distúrbio Dissociativo, Distúrbio Dimórfico Corporal, entre outros (Sanderson, 2005).

Além de tudo o exposto, Aded (2006) também fala do aumento da possibilidade de um indivíduo que sofreu abuso apresentar comportamentos autodestrutivos, dificuldade nos relacionamentos sexuais, ideações paranoides, Transtorno Obsessivo Compulsivo (TOC) e Transtorno de Conversão, neste último caso especialmente quando há histórico de abuso de longa duração e relações incestuosas. O autor aponta também para a perda de interesse pelos estudos e brincadeiras, dificuldades em se ajustar, isolamento social, déficit de linguagem e aprendizagem, uso de álcool e drogas, ideias suicidas e homicidas, automutilação, tentativas repetidas de suicídio, entre outros.

Sabe-se que, na maioria dos casos, os perpetradores são pessoas que fazem parte do universo da criança (Aded, 2006). Como ressalta Sanderson (2005, p. 20) “em muitos aspectos, abusadores sexuais de crianças são pessoas comuns que as crianças encontram em sua vida cotidiana". Logo, a violência pode ser cometida por um familiar, constituindo um abuso sexual intrafamiliar, ou seja, quando este ocorre com pessoas possuidoras de laços afetivos e parentais, podendo ser entendido, assim, como incesto (Florentino, 2015).

Tendo isto em mente, podemos nos questionar de que forma o fato de o perpetrador ser alguém próxima à criança poderá impactar na vida da vítima e se tal impacto é relevante. Primeiramente é necessário ressaltar que uma pessoa que faz parte do cotidiano da criança é detentora de sua confiança. Uma vez que esta confiança seja quebrada devido ao abuso sofrido pela criança é possível que haja maiores prejuízos por parte desta (Sanderson, 2005).

Assim, "os casos de abuso sexual intrafamiliar, a família, que deveria representar um local seguro para seus membros, torna-se um espaço de insegurança, medo desconfiança, conflito e de incerteza entre o que é certo e errado" (Florentino, 2015, p. 143). Logo, é possível que a criança desenvolva dificuldades de confiar em alguém, o que pode gerar por sua vez problemas em seus relacionamentos na vida adulta posteriormente havendo, ainda como consequência do abuso sexual intrafamiliar, o comprometimento da capacidade de estabelecer vínculos afetivos com seus pares.

Importante que se considere também que devido ao fato de a maioria dos casos de abusos sexuais serem praticados por familiares ou pessoas ligadas à criança, muitos dos casos caem na omissão e no silêncio constituindo, assim, um segredo o qual é apontado como outro aspecto que compromete a vida da criança e do adolescente (Florentino, 2015).

Há evidências clínicas de que a revelação do abuso sexual sofrido tem um efeito positivo nas crianças quanto ao lidar com as experiências levando-as a processar e integrar o ocorrido. Por outro lado, guardar o "segredo" potencializam o impacto da violência na vida das vítimas (Sanderson, 2005). Florentino (2015) confirma tais afirmativas ao afirmar que o segredo, alimentado pela angústia de não contar por medo do agressor ou por não ser acreditado pela genitora ou os demais familiares, causa diversos comprometimentos psicológicos.

Quanto aos pais ou responsáveis da criança abusada, estes permanecem muitas vezes calados, impotentes, frente à situação. Esta atitude de calar causa uma desorganização nos papéis ocupados pelos membros da família que, a partir do abuso, colocam-se inconscientemente frente a uma incapacidade de discriminação de limites, evidenciando uma relação de poder, sedução e submissão (Lopes; Torman, 2008).

Assim, tendo em vista as possíveis consequências de um abuso sexual sofrido na infância e sabendo que esta forma de violência acarreta grandes prejuízos não apenas físicos, mas também, emocionais e psicológicos, podemos nos perguntar de que maneira tudo isto impactará o processo de aprendizagem da criança e quais seus reflexos na construção das modalidades de aprendizagem já que este se molda a partir das relações. Ora, se devido ao abuso na infância é possível que ocorra comprometimentos afetivos e relacionais da criança para com seus pares, é possível inferir que isto terá relevância na relação aprendente/ensinante do indivíduo violentado. 
Também, é possível levantar questões quanto a forma de aprender da criança abusada mediante o segredo familiar que se estabelece em alguns casos. De que possível forma isso poderá refletir na criança quando, por exemplo, esta encontra-se na escola, lugar onde revela-se o que sabe? O segredo, poderá se refletir no processo de aprendizagem? Se sim, de que maneira?

Tais reflexões fazem-se mister para a compreensão de possíveis situações envolvendo abuso sexual infantil com que o psicopedagogo poderá se confrontar em sua prática e, ainda, de como ele poderá atuar nestes casos, tendo em mente a situação de fragilidade em que se encontram algumas crianças que sofrem este tipo de violência.

\subsection{A psicopedagogia em casos de abuso sexual infantil: um caminho possível}

Considerando que o abuso sexual vivenciado na infância pode se refletir na forma de apreender o conhecimento do indivíduo violentado, é necessário pensar de que possível forma o psicopedagogo poderá atuar junto a este de modo efetivo, abrangendo tanto uma ação preventiva quanto terapêutico.

Sabe-se que o enfoque preventivo deverá visar, dentre outras coisas, diminuir a frequência dos problemas de aprendizagem, assim como diminuir, tratar e eliminar os problemas já instalados, neste caso específico, aqueles decorrentes da violência sexual vivida.

Assim, podemos então apontar que, neste sentido, o trabalho preventivo poderá ser efetuado no espaço institucional escolar, local onde ocorre grande parte da formação do ser humano sendo este responsável pela aprendizagem formal.

Tendo em mente que a Psicopedagogia Educacional "deixou de ser um atendimento individualizado ao aluno com dificuldades de aprendizagem, tornando-se um trabalho colaborativo junto à equipe da escola” (Masini, 2015, p. 72) é possível prever que na sua função preventiva o psicopedagogo poderá realizar um trabalho que promova orientação metodológica, além de participar da dinâmica das relações da comunidade educativa a fim de favorecer processos de integração e troca (Bossa, 2000).

Quanto a este aspecto do trabalho psicopedagógico, pode-se enfatizar a possibilidade de promover ações que visem à aprendizagem do autocuidado, sendo possível inclusive quando este é responsável “[...] pela elaboração, direção e evolução de planos, programas e projetos no setor de educação e saúde, integrando diferentes campos do conhecimento" (Bossa, 2000, p. $30)$.

A aprendizagem do autocuidado pode estar relacionada à prevenção do abuso sexual em crianças e deve ser também foco de atuação do psicopedagogo neste sentido já que esta "não é apenas responsabilidade de pais, professores, agentes de órgãos governamentais de proteção infantil e da polícia. É uma responsabilidade que todos os adultos da comunidade precisam compartilhar" (Sanderson, 2005).

Considerando que o psicopedagogo deve estar consciente do fato de que sua atividade consiste também em transmitir conhecimento (Mery, 1985), a aprendizagem do autocuidado deve envolver a conscientização quanto aos riscos do abuso sexual, sendo essencial que sejam oferecidas informações corretas, não apenas às crianças, mas também aos pais e aos professores, assim como a todos os adultos. Esta aprendizagem deve incluir também aspectos relacionados ao reconhecimento e diferenciação de comportamentos adequados e inadequados entre adultos e crianças impedindo que estas últimas considerem normais suas experiências e, por isso, se mantenham em silêncio (Sanderson, 2005).

Além de todo o exposto, uma promoção de uma aprendizagem de autocuidado deve possibilitar, dentre outras coisas, que as crianças possam compartilhar suas experiências e discuti-las sem se sentirem embaraçadas ou culpadas.

Ao promover a aprendizagem de autocuidado o psicopedagogo, além de prevenir o abuso sexual em crianças, estará também contribuindo na prevenção de problemas relacionados à aprendizagem de ordem sintomática em reflexo do trauma que $\mathrm{o}$ ato violento pode acarretar. 
No trabalho terapêutico o psicopedagogo tratará as dificuldades de aprendizagem. Aqui, interessa-nos abordar aqueles atrelados especificamente à experiência do abuso sexual vivenciada na infância sendo estas, portanto, de ordem sintomáticas.

Os problemas de aprendizagem estão relacionados, como vimos anteriormente, à perda de mobilidade da modalidade de aprendizagem e ao enrijecimento dela. Como ensina Fernández (1991, p. 112), “[...] um sintoma-problema de aprendizagem vem instalar-se sobre uma modalidade já existente, que o sujeito construiu desde o nascimento, em que intervêm significações ainda anteriores a ele mesmo". O sintoma, portanto, emerge da modalidade modificando-a, geralmente enrijecendo-a, cristalizando-a num determinado momento.

O sintoma é aquilo que é percebido pelo indivíduo ou pelos outros e "[...] está sempre mostrando algo, é um epifenômeno. Com o sintoma o sujeito sempre 'diz alguma coisa aos outros', se comunica, e 'sobre o sintoma sempre se pode dizer algo"” (Weiss, 2002, p. 28).

Quando se busca alterar a modalidade de aprendizagem é necessário focalizar, portanto, o ponto especial de articulação entre a elaboração subjetivante e objetivante. Para isto analisa-se a modalidade de aprendizagem, já que o trabalho psicopedagógico perpassa a compreensão deste esquema, mas leva-se em conta também à significação que outorgue o sujeito a esse operar.

Dessa forma, o trabalho psicopedagógico num enfoque terapêutico interventivo não se dirige ao sintoma, mas a poder mobilizar objetivamente e subjetivamente tendo sempre em vista que a aprendizagem ocorre não só a partir de conceitos, mas também a partir da história de trocas que cada um de nós teve, das imagens, das lembranças e das fantasias sobre os objetos apreendidos (Fernández, 1991).

Portanto, o psicopedagogo deve atuar de modo que favoreça esta mobilização objetivante e subjetivante do sujeito que apresenta um sintoma que emerge da modalidade de aprendizagem. Neste processo, é importante, dentre outras coisas, que o psicopedagogo perceba as diferentes formas de interação da família, dirigindo a sua intervenção aos fatores envolvidos na formação do sintoma a fim de mobilizar a modalidade de aprendizagem do sujeito e da sua família (Braga, Scoz \& Munhoz, 2007).

Desse modo, considerando que um dos possíveis prejuízos que uma criança abusada sexualmente apresenta se dá nas relações e vínculos afetivos, importante que o psicopedagogo esteja ciente deste fato, visto que estes são algumas das ferramentas utilizadas por ele na sua prática interventiva.

Bossa (2000) ressalta que no aprender do ser humano participam aspectos cognitivos, socioculturais, mas também afetivos. Portanto, o aspecto afetivo é um importante fator a ser considerado quando se almeja compreender o processo de aprendizagem de um determinado sujeito (Sisto \& Martinelle, 2006).

Logo, na intervenção psicopedagógica que envolve um sujeito abusado, o profissional deve atuar de modo que possa vir a possibilitar o estabelecimento do vínculo afetivo ao mesmo tempo em que lança mão deste aspecto para a efetivação do seu trabalho, reconhecendo a sua própria subjetividade na relação, o que implica uma temática complexa neste processo.

Ao utilizar-se da afetividade como instrumento para auxiliar o sujeito a lidar com as possíveis marcas desfavoráveis em sua modalidade de aprendizagem o psicopedagogo dará condições à criança de ressignificar a história que recebeu, onde aqui se inclui a experiência do abuso, e conectar-se com o prazer de ser autor (Braga, 2007). A ressignificação significa então a possibilidade de que a modalidade de aprendizagem possa ir se modificando e, a partir dessa mobilização, é possível que se relativize os fatores que constroem o sintoma (Fernández,1991).

Abaixo, um quadro explicativo mostra as possíveis formas de atuação do psicopedagogo nos casos de abuso sexual infantil. 
Figura 1: Possíveis rotas de atuação do Psicopedagogo em casos de abuso sexual.

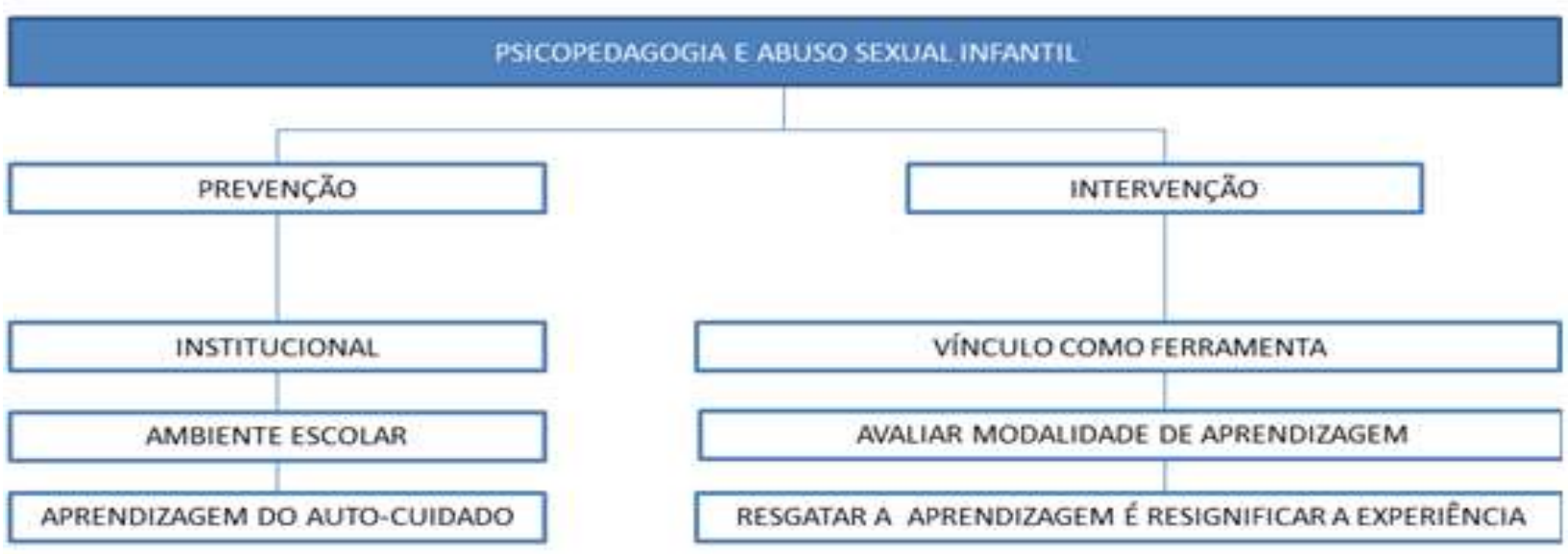

Fonte: Autores (2021).

Disso é possível inferir a existência de uma correlação da mobilidade de aprendizagem e a ressignificação do abuso sofrido. Isto faz sentido já que, a modalidade de aprendizagem do sujeito é uma expressão de sua personalidade, do mesmo jeito que a personalidade estabelece a modalidade de aprendizagem (Valle, 2009).

Portanto, neste processo em que a criança se torna autor da própria história e ressignifica a experiência abusiva, o trabalho psicopedagógico, como vimos, tem papel relevante e se apresenta “[...] como uma possibilidade, sendo que é um campo de conhecimento que percorre diferentes caminhos na busca do motivo do não aprender, dos sujeitos que trazem a marca do sofrimento do abuso sexual" (Lopes \& Torman, 2007, p. 118).

Neste processo, o papel do psicopedagogo, segundo Braga (2007), é o de facilitador, o qual não foi encontrado na família, sendo necessário para que ocorra o desenvolvimento da espontaneidade, base criativa e do desenvolvimento da capacidade de interessar-se e envolver-se na aprendizagem.

\section{Considerações Finais}

Através deste trabalho foi possível perceber que a aprendizagem é um processo abrangente e que vários aspectos estão envolvidos. Esse processo perdura durante toda a vida do indivíduo desempenhando papel importante para a sua sobrevivência e para a transmissão das aquisições culturais de uma civilização estando, portanto, para além da capacidade de aquisição de conhecimento.

Diante das várias definições e das diversas perspectivas quanto à aprendizagem que foram apresentadas no trabalho, ficou evidente o fato de estar longe de se encerrar a compreensão deste processo ante sua complexidade. Foi ponto preponderante neste estudo a definição de modalidade de aprendizagem que apontam como sendo a forma única e particular do indivíduo se relacionar com o conhecimento onde, no processo de construção dessa modalidade, estão relacionados aspectos como a história de vida do sujeito, as relações interpessoais e os vínculos que existentes nestas relações. Foi ressaltado ainda que, é quando tal estrutura torna-se enrijecida perdendo sua fluidez que é possível falar de uma patologia do aprender. Esse conceito muito contribuiu para discutirmos as repercussões da vivência de um abuso sexual na infância para a aprendizagem.

Dessa forma, como a maneira de aprender é perpassada pela história de vida do sujeito e das relações familiares afetivas/emocionais, o desenvolvimento do presente trabalho permitiu concluir não só que o processo de aprendizagem pode sofrer impactos em consequência da experiência do abuso sexual e do trauma decorrente deste, mas também pode definir os modelos de interação do indivíduo com a realidade. 
Dentre os reflexos no processo de aprendizagem possíveis de serem inferidas e que foram apresentados neste estudo, apontam-se aqui, por exemplo, para o contato empobrecido com o objeto de saber em decorrência do medo e confusão da criança que projeta no professor a figura do abusador ou ainda para uma criança que apenas cumpre instruções indiscriminadamente sem, contudo, dispor de suas próprias experiências prévias onde possivelmente ocorre uma autoestima prejudicada em consequência da violência sofrida. Também, decorrente da possibilidade de que ocorram distorções da realidade, a criança pode aprender a partir de uma visão desrealizada, sem que haja uma interpretação adequada da realidade externa.

Tendo em mente que algumas vítimas de abuso buscavam apoio em seus professores, fazendo deles alvo de uma confiança muitas vezes não encontrada em casa ao falar de suas experiências dolorosas, houve o interesse e a necessidade de melhor compreender a vulnerabilidade e a fragilidade com que muitas dessas crianças e adolescentes se encontravam e de como o professor poderia oferecer alguma ajuda.

Infelizmente, no contexto escolar, alguns casos de crianças e adolescentes que sofreram abuso sexual chegaram até mim despertando uma inquietação quanto às possíveis reverberações no processo de aprendizagem. A preocupação do pesquisador, na maioria das vezes, relacionava-se exatamente às possíveis projeções dessas crianças e de como uma atitude, uma fala, ou uma postura do pesquisador poderia remeter-lhes aos seus abusadores. Posteriormente, os pesquisadores se interessaram em compreender até que ponto o comportamento e a aprendizagem desses sujeitos eram norteados pelas vivências do abuso sexual, chamando a atenção, muitas vezes, para os prejuízos emocionais apresentados por eles que, por vezes, eram acompanhados de baixa autoestima.

Por fim, tendo nos deparado com estas situações no contexto escolar no exercício do papel de professor e diante da possibilidade de que tal fato possa ocorrer também na atuação psicopedagógica, ocorreu-nos então de pesquisar trabalhos, artigos e monografias voltados para esta área e que tratassem dessa temática. No entanto, diante dos resultados obtidos, que foram poucos, tomamos este fato como impulso para desenvolvê-lo tendo em mente a complexidade e a delicadeza do assunto.

No entanto, enfatizamos aqui que o trabalho psicopedagogo não substitui de forma nenhuma o trabalho psicoterapêutico. Tendo experienciado o abuso sexual, a criança deverá ser acompanhada por um psicólogo a fim de realizar um trabalho que vise minimizar os possíveis danos emocionais e psíquicos dela. Assim, o trabalho realizado pelo psicopedagogo deverá ser multidisciplinar, não apenas com psicólogos, mas também com outros profissionais mediante a gravidade do abuso. Portanto, embora o trabalho do psicopedagogo possa ser de enorme ajuda ao indivíduo violentado, este profissional deve estar consciente da limitação do campo psicopedagógico e do que compete à sua área de atuação.

\section{Referências}

Aded, N. L. O. de, Dalcin, B. L. G. S. da, Moraes, T. M. de, \& Cavalcanti, M. T. (2006). Abuso sexual em crianças e adolescentes: revisão de 100 anos de literatura. Archives of Clinical Psychiatry (São Paulo), 33(4), 204-213. https://dx.doi.org/10.1590/S0101-60832006000400006

Almeida, A. P. D. de. (2011). Quando o vínculo é doença: a influência da dinâmica familiar na modalidade de aprendizagem do sujeito. Revista Psicopedagogia, 28(86), 201-213. http://pepsic.bvsalud.org/scielo.php?script=sci_arttext\&pid=S0103-84862011000200011\&lng=pt\&tlng=pt.

Bossa, N. (2000) A Psicopedagogia no Brasil: Contribuições a partir da prática. (2a ed). Artmed.

Braga, S. S. da, Scoz, B. J. L., \& Munhoz, M. L. P. (2007). Problemas de aprendizagem e suas relações com a família. Revista Psicopedagogia, 24(74), 149159. http://pepsic.bvsalud.org/scielo.php?script=sci_arttext\&pid=S0103-84862007000200006\&lng=pt\&tlng=pt..

Brasil. (1990). Senado Federal. Lei 8.069/90, de 13 de Julho de 1990. Estatuto da Criança e do Adolescente. Brasília: Senado Federal.

De Antoni, C., Yunes, M. A. M., Habigzang, L., \& Koller, S. H. (2011). Abuso sexual extrafamiliar: percepções das mães de vítimas. Estudos de Psicologia (Campinas), 28(1), 97-106. https://doi.org/10.1590/S0103-166X2011000100010.

Fernández, A. (1991) A inteligência aprisionada.Tradução de Iara Rodrigues. Artmed Editora.

Fonseca, J. J. S. da. (2002). Metodologia da pesquisa científica.: UECE. 
Research, Society and Development, v. 10, n. 12, e39101220047, 2021

(CC BY 4.0) | ISSN 2525-3409 | DOI: http://dx.doi.org/10.33448/rsd-v10i12.20047

Florentino, B. R. B. (2015). As possíveis consequências do abuso sexual praticado contra crianças e adolescentes. Fractal: Revista de Psicologia, 27(2), 139144. https://doi.org/10.1590/1984-0292/805

Garcia-Rosa, L. A. (2009). Freud e o Inconsciente. Jorge Zahar.

Ghiraldelli Junior, P. (2008). História da Educação no Brasil. (3a. ed.) Cortez.

GIL, A. C. (2007). Como elaborar projetos de pesquisa. (4a ed.) Atlas.

Lopes, K. C. de, \& Torman, R. (2008). O abuso sexual e a inclusão momentânea: as conseqüências no processo de aprendizagem. Revista Psicopedagogia, 25(77), 132-138. http://pepsic.bvsalud.org/scielo.php?script=sci_arttext\&pid=S0103-84862008000200005\&lng=pt\&tlng=pt. .

Masini, E. F. S. (2015). O Psicopedagogo na Escola. Cortez.

Mery, Janine. (1985). Pedagogia Curativa Escolar e Psicanálise.: Artes Médicas.

Mello, L. C. A. de, \& Dutra, E. (2008). Abuso sexual contra crianças: em busca de uma compreensão centrada na pessoa. Revista da Abordagem Gestáltica, 14(1), 39-47. http://pepsic.bvsalud.org/scielo.php?script=sci_arttext\&pid=S1809-68672008000100007\&lng=pt\&tlng=pt.

Nunes, A. I. B. \& Silveira, R. N. (2008). Psicologia da aprendizagem: processos, teorias e contextos (3a ed.).: Liber Livro.

Paín, S. (1985). Diagnóstico e Tratamento dos Problemas de Aprendizagem (Tradução de Ana Maria Netto Machado). Artmed.

Postman, N. (1999). O Desaparecimento da Infância. Tradução de Suzana Menescal de A. Carvalho e José Laurenio de Melo. Grafhia Editorial.

Rudges, A. M. (2009). Trauma. Rio de Janeiro: Jorge Zahar.

Sanderson, C. (2005). Abuso Sexual em Crianças: fortalecendo pais e professores para proteger crianças contra abusos sexuais e pedofilia. Tradução: Frank de Oliveira. São Paulo: M. Books do Brasil Ltda.

Santos, M. S. dos, Xavier, A. S., \& Nunes, A. I. B. L. (2008). Psicologia do Desenvolvimento: teorias e temas contemporâneos. Liber Livro.

Sisto, F. F. \& Martinelli, S. C. de. (2006). Afetividade e dificuldades de aprendizagem: uma abordagem psicopedagógica. Vetor.

Stupiggia, M. (2010). O Corpo Violado: uma abordagem psicocorporal o trauma do abuso. (Tradução de Roberto Chiattone e Nelson Patriota). EDUFRN.

Valle, T. G. M. do (org.). (2009). Aprendizagem e desenvolvimento humano: avaliações e intervenções. Cultura Acadêmica.

Weiss, M. L. (2002). Psicopedagogia Clínica: uma visão diagnóstica dos problemas de aprendizagem escolar (9a ed.). DP\&A. 